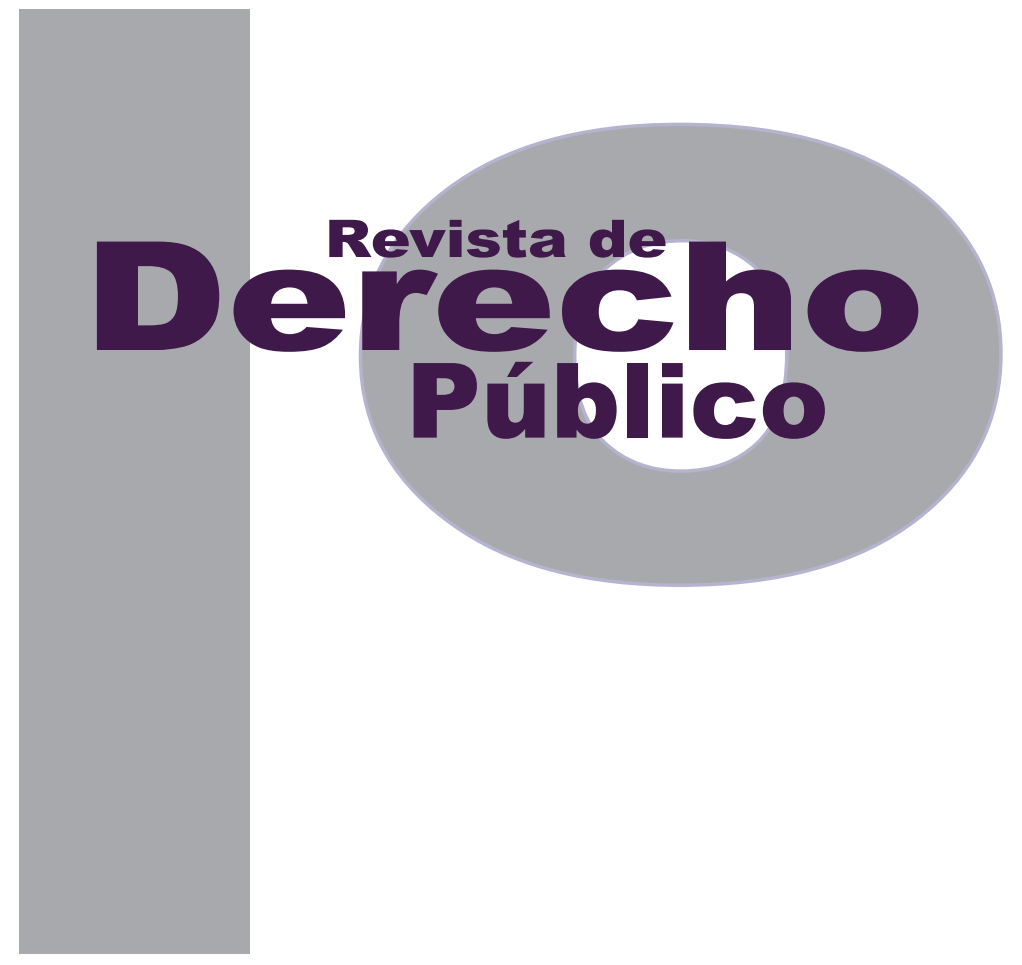

\title{
LA PRESENTACIÓN CUIDADOSA, CLARA, PRECISA Y RESPETUOSA DEL ARGUMENTO
}

\author{
John Freddy SAZA Pineda
}

Universidad de los Andes

Facultad de Derecho

Revista de Derecho Público N. ${ }^{\circ} 32$

Enero - Junio de 2014. ISSN 1909-7778 


\title{
La presentación cuidadosa, clara, precisa y respetuosa del argumento*
}

\author{
John Freddy Saza Pineda**
}

\section{RESUMEN}

El presente artículo pretende evidenciar las razones por las cuales es aconsejable presentar argumentos de manera cuidadosa, clara y respetuosa en el contexto de las discusiones judiciales.

PALABRAS ClAVE: argumento, argumentación, justificación, gramática, palabra, claridad, precisión, respeto.
This article aims to demonstrate the reasons why it is advisable to present careful, clear and respectful arguments in the context of judicial discussions.

KEY WORDS: argument, justification, grammar, Word, clarity, accuracy, respect.

Cómo citar este artículo: Saza Pineda, J. F. (Junio, 2014). La presentación cuidadosa, clara, precisa y respetuosa del argumento. Revista de Derecho Público, 32.

** Abogado y especialista en Instituciones de Derecho Procesal de la Universidad Nacional de Colombia; especialista en Derecho Contractual y Relaciones Jurídico Negociales de la Universidad Externado de Colombia; especialista en Argumentación Jurídica de la Universidad de Alicante (España); magíster en Derecho de la Universidad Nacional de Colombia; exmagistrado auxiliar de la Sala de Casación Civil de la Corte Suprema de Justicia; profesor de Teoría General del Proceso, Derecho Probatorio, Derechos Reales, Contratos, Sociedades, Sucesiones y Argumentación Jurídica de las Universidades Nacional de Colombia, Católica de Colombia, El Bosque y los Andes. 



\section{SUMARIO}

Introducción - I. DESARROLLO - A. La presentación cuidadosa del argumento - B. La presentación clara y precisa del argumento - C. La presentación respetuosa del argumento - II. CONCLUSIONES - Referencias. 


\section{Introducción}

Para nadie es un secreto que en el escenario judicial no basta tener conocimiento de las materias sustanciales debatidas, ni es suficiente con saber la forma y los términos de las etapas procesales que deben seguirse. A esas habilidades hay que sumarle, además, la capacidad de transmitir los argumentos de manera adecuada, todo con miras a lograr el convencimiento o la persuasión del auditorio.

Partiendo de esa base, este artículo tiene como propósito reflexionar críticamente sobre la necesidad de hacer un adecuado uso del lenguaje en las controversias judiciales, tanto en aquellas etapas que se surten en forma escrita como en las audiencias y diligencias, en las que se precisa una comunicación oral.

Se trata, entonces, de traer a colación razones por las cuales los contendientes deben propender por lograr una comunicación caracterizada por la claridad, la precisión y el respeto, en aras de que sus argumentos tengan mayor fuerza en la discusión.

Con ese propósito, se hacen algunas referencias a autores - principalmente a Arthur Schopenhauer- que, desde su perspectiva, demuestran cómo un adecuado uso del lenguaje sienta las bases para una argumentación más consistente.
I. DESARROLLO

No tenemos otra cosa [salvo las palabras]. Somos las palabras que usamos. Nuestra vida es eso. (José Saramago)

En un episodio de la satírica, entretenida y extravagante obra del escritor francés François Rabelais, titulada Gargantúa y Pantagruel, el autor detalla cómo "en la Corte estaba a la sazón pendiente un pleito entre dos grandes señores... controversia muy ardua y difícil desde el punto de vista del Derecho... Tanto se prolongó la polémica judicial que el veredicto no llegaba nunca, mientras los litigantes envejecían, corriendo el riesgo de morir con la duda de cuál de los dos tenía la razón..." (2003, p. 162).

Al ser consultado sobre el caso, el gigante Pantagruel, quien recibía constantes halagos por su "portentosa inteligencia", decidió escuchar a las partes, se reunió con "los presidentes, consejeros y doctos allí presentes", se paseó un par de veces por la sala, caviló profusamente, se sentó y tras sus reflexiones pronunció con voz de autoridad la siguiente sentencia:

El Tribunal decide: que considerando la horripilación del murciélago declinado bravamente del solsticio estival para cotejar las consejas que ha sufrido mate al peón por las malvadas vejaciones de los lucífugos, inquilinos de los climas que pasan por Roma con una gimelga a caballo que se venda los riñones con una ballesta, el demandante tuvo justa causa para calafatear el guante que la buena mujer infló con un pie descalzo y otro desnudo, reembol- 
sándosele, bajo roído en su conciencia, tantas bagatelas como pelos haya en dieciocho vacas, y otro tanto para el bordador...

... Tras haber pronunciado esta sentencia las dos partes se fueron con gran contento, cosa que resulta casi increíble, pues jamás había sucedido desde el diluvio, ni volverá a suceder en trece jubileos, que dos partes contendientes en un juicio contradictorio se muestren igualmente satisfactorias con una sentencia definitiva (Rabelais, 2003, pp. 162-168).

El episodio anterior, aunque constituye una descripción caricaturesca y metafórica de un aparente escenario judicial, es pertinente para analizar críticamente cómo en ocasiones la exposición de los argumentos jurídicos es tan inextricable, confusa y descuidada, que aquellos resultan de difícil entendimiento para sus destinatarios y, en todo caso, no permiten descubrir lo que verdaderamente se ha querido expresar.

Ello, por supuesto, afecta las reglas fundamentales del discurso práctico racional en el ámbito jurídico, no solo porque es imposible "asegurar un lenguaje claro y con sentido" para lograr una verdadera comunicación analítico-lingüística (Alexi, 2008), sino además porque se restringe la deliberación y el disenso, amén de que se disminuyen notablemente las posibilidades de convencer o persuadir al juez, a las partes o al auditorio, según la arista que se deba asumir en el debate.

De la mano de lo anterior, hay que decir que la argumentación oscura, ambigua o alambicada afecta el derecho fundamental al debido proce- so, pues impide a los interesados conocer los verdaderos confines de la discusión y, de paso, limita la posibilidad de defenderse o controvertir de manera idónea los fundamentos de una determinada posición jurídica.

A la postre, en este tipo de eventos no se puede descifrar la manera como se construyó el argumento, ni la veracidad o corrección de las premisas, ni la consecuencialidad del resultado, esto es, que resulta altamente complejo determinar la forma como se desarrollaron los procesos de justificación interna y externa del silogismo jurídico que se presenta como fundamento de la decisión (Atienza, 2010).

Ahora bien, en varias recopilaciones de escritos de Arthur Schopenhauer, tituladas El arte de insultar, El arte de tener la razón y El arte de hacerse respetar, el filósofo alemán, caracterizado por su escepticismo crítico, pero también por su análisis juicioso sobre las diferentes formas de lograr el éxito en una discusión, lanza una serie de discernimientos prácticos que, pese a su lenguaje mordaz, a no dudar brindan pistas valiosas para la presentación afortunada de los argumentos en una contienda jurídica, ya sea escrita o verbal.

De las opiniones de dicho autor se infieren tres aspectos que han de observarse a la hora de argumentar: uno de presentación, otro de precisión y, finalmente, otro de respeto. 


\section{A. La presentación cuidadosa del argumento}

En cuanto a la presentación cuidadosa del argumento, especialmente por escrito, el filósofo expone un epigrama tan sutil, como contundente: "quien escribe en forma descuidada da testimonio, por lo pronto, de que no le atribuye demasiado valor a sus propios pensamientos" (Schopenhauer, 2007b, p. 65). El descuido al que allí se hace referencia tiene que ver, entre otras cosas, con la desatención a las normas básicas que permiten el uso adecuado del lenguaje escrito, esto es, las reglas de morfología, ortografía, semántica y sintaxis. A la larga, como él mismo señala, la obra de la gramática "es estudiar ese lenguaje, para traerle a la luz de la reflexión y de la clara conciencia" (Schopenhauer, 1998, p. 51).

No puede perderse de vista que

la redacción del texto jurídico exige unos conocimientos mínimos del lenguaje. Redactar es un trabajo y, como dice María Teresa Serafini (Serafini, 1989), para hacer un trabajo es necesario esfuerzo, pero especialmente conocer las reglas del oficio. Esas reglas del oficio son las reglas de la gramática, la sintaxis, la semántica y la pragmática. Además de los aportes de esas disciplinas, actualmente en el área de la lingüística se estudia una nueva área que se ha denominado la 'ciencia del texto', que también tiene mucho que aportar en el estudio y producción del texto jurídico (Cano Jaramillo, 1996, p. 50).

Por supuesto que alguien podría afirmar, con Óscar Wilde, que "no existen más que dos reglas para escribir: tener algo que decir, y decirlo"
(Gómez Díaz, 2002, p. 567).

No obstante, es evidente que un buen argumento brilla más cuando aparece correctamente redactado, pues permite una mayor comprensión y refleja, cuando menos, un esfuerzo por comunicarse de forma adecuada, cosa que, de por sí, ya es un logro; contrario sensu, un argumento puede perder importancia si se desvanece entre errores de gramática, no solo porque este tipo de yerros denotan ligereza o desconocimiento de las normas cardinales del lenguaje, sino además porque fuerzan la atención del lector y crean distractores que a la larga impiden que su valor persuasivo cale de forma contundente, si no es que, en el peor de los casos, originan confusiones que terminan por arruinar completamente la idea que se pretende defender.

De ahí la sentencia de Saramago: "si las palabras se usan mal, si se tergiversan, si se pronuncian mal, como ocurre muchas veces, ¿qué pensamiento van a expresar? Eso es frustrante" (Gómez Aguilera, 2010, p. 243).

Precisamente por ello, la Ley Estatutaria de la Administración de Justicia exige en su artículo 55 "la pulcritud del lenguaje" en la redacción de las providencias judiciales, mensaje que de por sí es bastante diciente en el entorno de la lid procesal y que, obviamente, se extiende a todos los sujetos que participan de ese espacio de comunicación, máxime cuando las nuevas tecnologías ponen al servicio de los operadores jurídicos un sinnúmero de instrumentos que contribuyen a mejorar la ortografía, la redacción y la sintaxis. 
A la postre, debe tenerse siempre presente que la palabra es el insumo principal de los protagonistas del debate jurídico, lo que demanda disciplina y rigor en su uso, pues no de otra forma se asegura una comprensión racional del argumento. Como otrora dijera un reconocido doctrinante,

el arte del Derecho se hace con la palabra. A través de la historia, el Derecho se ha valido de la palabra para su estructuración y como principio de su funcionamiento. Aun en los pueblos cuyo Derecho se funda en lo acostumbrado, la palabra sigue siendo el medio, el único medio para conservar el orden de su organización. Recordemos que la ley representa y dispone con la palabra, que el acto y el hecho se describen y explican mediante la palabra, que el juicio se forma en la palabra, que el Derecho se establece y transmite por la palabra, que la interpretación se conforma a través de la palabra y que el Estado se manifiesta haciendo uso de ella. La palabra viene a ser el material imprescindible del arte del Derecho. Para el juez y el legislador, la palabra es lo que el color a los pintores, el metal, la piedra y el barro al escultor, o el sonido al músico (Medellín, 1995, p. 29).

Por supuesto que la pulcritud del lenguaje también es deseable cuando de argumentaciones orales se trata, es decir, cuando el debate judicial se desarrolla a través de audiencias. Aquí, las palabras surgen de viva voz y, entonces, el cuidado debe ser en la entonación, en el volumen y en la dicción. También cobra importancia el lenguaje del cuerpo, que debe ser consecuente, coordinado y refinado. ${ }^{1}$ No en vano, se dice

Han de apreciarse, entonces, los gestos, la forma y la ubicación de la mirada, la expresión facial, el uso de las manos, los movimientos del cuerpo, la imagen y el aspecto personal, entre otras cosas. que "en el buen orador se agrupan la facilidad de expresión o fluidez de la palabra y armonía y coordinación de la expresión corporal" (Cano Jaramillo, 1996, p. 319).

Al fin y al cabo, "las habilidades y destrezas orales no son herramientas para convertir al abogado en un actor, ni siquiera en un orador excelente, sino en un orador efectivo" (Reyes Medina, 2003, p. 41), y ello supone de antemano que la expresión oral sea cuidadosa, correcta y prolija, máxime cuando dadas las características de este tipo de juicios, "con facilidad se puede perder el contacto intelectual, emocional y físico con el auditorio", de modo que "las partes deben manejar con responsabilidad" el lenguaje, "sabiendo qué dicen y porqué lo dicen, lo cual exige una plena comprensión intelectual de los conceptos y de los juicios que se usan" (Cano Jaramillo, 1996, p. 320) y, por supuesto, de las palabras que se utilizan para construirlos.

\section{B. La presentación clara y precisa del argumento}

En lo que tiene que ver con la claridad y precisión, Schopenhauer (2007b) se muestra apático a la idea de expresarse de manera extensa y enredada. En esa dirección, afirma con toda contundencia que existen personas que "presentan sus pensamientos bajo un torrente de palabras con una prolijidad insoportable, como si fueran necesarios quién sabe qué prodigiosos recursos para hacer comprensible su sentido" (p. 101), a lo cual agrega: "algunos, para ocultar su carencia de auténticas ideas, se construyen un imponente andamiaje de palabras largas y 
compuestas, intrincadas fórmulas retóricas, periodos interminables, expresiones novedosas e inauditas, que den como resultado una jerga lo más difícil y erudita posible. Con todo eso, sin embargo, no logran decir nada..." (p. 101). Por supuesto que en un debate lleno de "delirantes constelaciones de palabras, en la que la mente se martiriza y agota tratando de sacar algo en limpio" (p. 110), la contundencia del argumento se desvanece, por más poderoso que sea.

Por regla general, las cuestiones -ya sean juridicas o fácticas- pueden presentarse de modo sencillo, digerible y entendible, o como suele decirse, con claridad meridiana. De ahí la máxima de Séneca: "es sencillo el lenguaje de la verdad; por lo tanto no lo debemos complicar" (1993, p. 207).

Es más, la presentación larga, compleja y farragosa de un argumento también puede generar la animadversión del lector, pues los discursos prolongados y repetitivos, además de agotadores y agobiantes, son muestra de que no se tiene un objetivo concreto, de que se alberga el propósito de confundir o, en todo caso, de que no hay seguridad o sinceridad en lo que se afirma.

Ese desacierto en la presentación de los argumentos se ve reflejado también en la utilización de citas o términos impertinentes, extensos y repetitivos, que no abordan de lleno el tema en discusión.

A veces, hasta suelen verse modelos preelaborados de argumentaciones escritas, en las que se hacen memorables reflexiones teóricas que no tienen nada que ver con el meollo del asunto y que terminan por desmotivar al lector, quien quisiera ahorrarse la lectura y conformarse solo con la parte donde se expresa el sentido de la decisión. Al fin de cuentas, como dijo Saramago, "las palabras cansan. Si nosotros pagáramos impuestos por las palabras, se enriquecerían Ios Estados. Creo que hablamos demasiado. No se necesitan tantas palabras. Mucho de lo que decimos es inútil", y luego añade: "decir de más es siempre decir menos” (Gómez Aguilera, 2010, pp. 230 y 273).

Respecto de lo anterior, la propia jurisprudencia ha dicho que

son en extremo defectuosos y reveladores de una deplorable pereza mental los fallos que se nutren de transcripciones tan innecesarias como impertinentes de casi todas las piezas del proceso, sin fijar, en forma clara y precisa, los hechos materia de debate, las pruebas que los respaldan y las conclusiones jurídicas a que haya lugar. Ellos responden al vicioso sistema, por desgracia bastante difundido... de hacer las providencias judiciales lo más largas, farragosas y confusas que sea posible, sin otro esfuerzo que el mecanográfico, para ocultar la pobreza o carencia de argumentos y la ignorancia o falta de estudio de los problemas a resolver (Corte Suprema de Justicia, Sala de Casación Civil, sentencia de 3 de junio de 1959).

Los poderes de síntesis, concreción y sencillez resultan, entonces, bastante útiles en la tarea de esgrimir los argumentos, paradigma que de hecho es defendido por el legislador, cuando pide que las súplicas de la demanda se presen- 
ten "con precisión y claridad" (art. 75 del C. de P. C. y art. 82 del C. G. del P.), o cuando reclama “la claridad, la precisión y la concreción de los hechos materia de los debates y de las pruebas que los respaldan" al elaborar las providencias judiciales (art. 55 de la Ley 270 de 1996).

Las bondades de la precisión y la claridad, ${ }^{2}$ asimismo, permiten un acceso fácil a los argumentos, denotan respeto por el tiempo del lector, evitan el desgaste de material humano y contribuyen a determinar los verdaderos contornos del problema jurídico en discusión, para de ese modo poder controvertirlos o evaluarlos, según el caso, en un marco de lealtad, transparencia y dinamismo. No se olvide que según enseñaba Aristóteles, "por definición... una virtud de la expresión es la claridad, pues un signo de esto es que si un discurso no hace patente algo, no cumplirá su función" (1990, p. 485).

En el escenario de la oralidad, la claridad también es fundamental; en ese sentido,

hay que evitar lo que resulte oscuro o ambiguo porque esto no favorece la estrategia personal, ni apoya el esclarecimiento de las ideas. La claridad es una auténtica virtud de la expresión, principalmente cuando el auditorio recibe las mismas ideas que intenta transmitir el orador... El mensaje claro es fácilmente comprendido, porque refleja organización, pensamiento diá-

2 A este respecto, Anthony Wetson anota lo siguiente: "quizás usted sepa exactamente lo que quiere decir, para usted todo está claro. Muchas veces, sin embargo, está lejos de ser claro para cualquier otra persona. Las cuestiones que a usted le parece que están relacionadas, a algún lector de su ensayo le pueden parecer totalmente desvinculadas. Es, por tanto, esencial explicar las conexiones entre sus ideas, aun si le parecen absolutamente claras... La claridad es tan importante para usted como es para sus lectores..." (2007, pp. 117118). fano, conceptos bien definidos, sintaxis correcta y léxico al alcance de la mayoría. En otras palabras, el estilo es claro cuando el pensamiento del que lo emite, llega sin esfuerzo a la mente del receptor (Cano Jaramillo, 1996, p. 325).

Justamente, como factores para alcanzar esa claridad en la argumentación oral, el mismo autor cita la elaboración de un plan; el uso de la oración; la separación coherente de los temas; la utilización de palabras o frases de enlace; la sencillez y naturalidad; y la precisión, entre otras cosas.

Aunado a lo anterior, la claridad de la argumentación entra a conjugar con los breves tiempos de que se dispone en los juicios orales. Como la intención es agilizar el proceso, la mejor manera de aprovechar los pocos espacios argumentativos que se brindan, es, por supuesto, siendo claro y contundente, pues de lo contrario, se corre el riesgo de no lograr blandir todos los argumentos que se pueden llegar a tener.

\section{La presentación respetuosa del argumento}

Finalmente, sobre la presentación respetuosa del argumento ha de memorarse cómo Schopenhauer (2007b) se refiere a la ofensa, y recuerda que "las naturalezas inferiores se sienten instintivamente compelidas a usarla en cuanto perciben la superioridad espiritual de alguien". A más de ello, pone de manifiesto que "una grosería... eclipsa cualquier intelecto" y que "quien insulta pone de manifiesto que no tiene nada sustancial que oponerle al otro...", para luego 
adicionar lo siguiente: “Toda grosería es en el fondo un recurso a la animalidad" en el que se sustituye el "conflicto de las fuerzas espirituales y del derecho moral, como su resolución por medio de razones", por "una lucha de las fuerzas brutas" (pp. 10, 12, 14 y 15).

De ese modo, quien al poner sobre la mesa sus argumentos acude al irrespeto, la grosería o la ofensa, ora expresa o ya soterradamente, corre el riesgo de ni siquiera ser escuchado, pero además -y todavía peor-, puede dejar la idea de que no tiene nada importante qué decir y que, por lo mismo, solo le quedan como herramientas el agravio y la provocación. También puede ser muestra de soberbia o desmesura, características ajenas por completo a la serenidad de quien pretende discutir racionalmente.

Sobre esa forma de argumentar, el mismo Schopenhauer, en otra de sus obras (2007c), expresa que "cuando se advierte que el adversario es superior y que uno no conseguirá llevar la razón, personalícese, séase ofensivo, grosero..." (p. 67). Entonces, si la discusión no se enfrenta con inteligencia, "que la verdad, el conocimiento, el espíritu y el ingenio vayan recogiendo sus cosas", pues pueden ser "barridos del campo por la divina grosería" (pp. 72 y 73).

A ello debe sumarse que una forma tal de presentar el discurso genera naturales resistencias, pues nadie recibe de buen agrado las manifestaciones que van contra el respeto y el decoro; y claro, de la resistencia puede pasarse, muy fácilmente, a la desaprobación, de suerte que en el ánimo del lector o del oyente queda un mal sabor, capaz de ensombrecer cualquier razón, por fundada que parezca. Por esa vía, entonces, un argumento que en principio tendría solidez, puede perder su fortaleza si se acompaña de improperios, arrogancia o descortesía.

Valga recordar las palabras de Aristóteles: “las expresiones... elegantes... tienen una mayor aceptación. El componerlas es propio, ciertamente, de quien posee una buena disposición natural y está ejercitado en ello..." (1990, p. 531), aserto compartido plenamente por Séneca al decir que "el enfermo no busca un médico elocuente. Pero si coincide que la misma persona que puede curar, expone con elegancia el tratamiento a seguir, el paciente lo considerará un bien" (1993, p. 358).

\section{CONCLUSIÓN}

Poner en práctica todo lo que viene de decirse demanda atención, disciplina, cuidado y voluntad, pero sobre todo, una alta dosis de trabajo y dedicación; lo que de todas formas no se puede perder de vista es que un buen argumento, correctamente escrito, sencillamente preciso y generosamente respetuoso, se potencializa y puede pasar a ser, sin lugar a dudas, más valioso y constructivo. Aquí, la combinación de la forma y el fondo abren la posibilidad de obtener un resultado más destacado y satisfactorio en los inhóspitos terrenos de la argumentación jurídica. 


\section{Referencias}

Alexi, R. (2008). Teoría de la argumentación jurídica. Madrid: Centro de Estudios Políticos y Constitucionales.

Aristóteles. (1990). La retórica. Madrid: Gredos.

Atienza, M. (2010). El derecho como argumentación. Barcelona: Ariel.

Atienza, M. (1993). Las razones del derecho. Madrid: Centro de Estudios Constitucionales.

Cano Jaramillo, C. A. (1996). La redacción del texto jurídico. Bogotá: Linotipia.

Corte Suprema de Justicia, Sala de Casación Civil. Sentencia de 3 de junio de 1959.

Gómez Aguilera, F. (2010). Saramago en sus palabras. Bogotá: Alfaguara.

Gómez Díaz, J. (2002). Antología del pensamiento humano. Bogotá: Editorial Gente Nueva.

Medellín, C. J. (1995). Introducción a la estética del derecho. Bogotá: Imprenta Departamental.
Rabelais, F. (2003). Gargantúa y Pantagruel. España: Edimat Libros.

Schopenhauer, A. (2007a). El arte de hacerse respetar. Madrid: Alianza Editorial.

Schopenhauer, A. (2007b). El arte de insultar. Madrid: Alianza Editorial.

Schopenhauer, A. (2007c). El arte de tener la razón. Madrid: Alianza Editorial.

Schopenhauer, A. (1998). Escritos literarios. México: Ediciones Coyoacán S. A.

Séneca. (1993). Epístolas morales a Lucilio. Barcelona: Planeta D’Agostini.

Serafini, M. T. (1989). Cómo redactar un tema. Madrid: Ediciones Paidos Ibérica S. A.

Reyes Medina, C. (2003). Técnicas del juicio oral en el Sistema Penal Colombiano. Reimpresión Segunda Edición. Bogotá: usAID.

Wetson, A. (2007). Las claves de la argumentación. Barcelona: Ariel. 